\title{
One-step Synthesis and Size Control of Tin/Indium (Sn/In) Nanowires by Surfactant-assisted Chemical Reduction Methods in Aqueous Solutions
}

\author{
Yang Shu', Qiyue Yin ${ }^{2}$, Joseph Benedict ${ }^{1}$, Guangwen Zhou ${ }^{2}$, Zhiyong Gu ${ }^{1, *}$ \\ 1. Department of Chemical Engineering \\ University of Massachusetts Lowell \\ One University Ave \\ Lowell, MA 01854, USA \\ 2. Department of Mechanical Engineering \& Multidisciplinary Program in Materials \\ Science and Engineering \\ State University of New York at Binghamton, \\ Binghamton, NY 13902, USA
}

*Corresponding author:

Phone: (1) 978-934-3540

Fax: (1) 978-934-3047

E-mail: Zhiyong_Gu@uml.edu 


\begin{abstract}
One dimensional tin/indium $(\mathrm{Sn} / \mathrm{In})$ nanowires have been synthesized through a surfactant assisted chemical reduction method in aqueous solutions at low temperature $\left(\sim 0{ }^{\circ} \mathrm{C}\right)$. Synthetic parameters such as stirring speed, injection rate of reducing agent, and alloy ratio were used to control the size and aspect ratio of the resulting nanowires. It was observed that the diameter of the nanowires was around $70 \mathrm{~nm}$ for all the synthesis conditions that were studied, whereas the length of the nanowires can be controlled in the range of $400 \mathrm{~nm}$ to $2 \mu \mathrm{m}$. The morphology and structure of the $\mathrm{Sn} / \mathrm{In}$ nanowires were characterized by field-emission scanning electron microscopy (FE-SEM), high-resolution transmission electron microscopy (HRTEM), and X-ray powder diffraction (XRD), and their thermal properties were measured by differential scanning calorimetry (DSC). Structure analysis indicated that the Sn/In nanowires were mainly composed of $\mathrm{InSn}_{4}$ and $\mathrm{Sn}$; no In3Sn phase was observed in the nanowires. DSC results confirmed the structures of the $\mathrm{Sn} / \mathrm{In}$ nanowires that were measured through XRD and indicated that the nanowires started to melt at a relatively low temperature around $118{ }^{\circ} \mathrm{C}$. Finally, a growth mechanism based on the reaction and structural evolution was proposed to explain the nanowire formation and growth process.
\end{abstract}

Keywords: Tin/Indium; lead-free solders; nanowires; chemical reduction; low temperature soldering; electronics assembly and packaging 


\section{Introduction}

In recent years, one-dimensional (1-D) nanostructures such as nanowires, nanorods, and nanotubes have drawn substantial attention, not only because of their unique structure that contributes to the fundamental understanding of the material behaviors, but also due to the outstanding electrical, optical, and magnetic properties that they exhibit, which may lead to new applications in different fields such as electronics, sensors, biomedical, environmental, and energy [1-6]. As sensing materials, metal, metal oxide, and semiconducting nanowires have been reported for the rapid detection of a variety of analytes, such as hydrogen peroxide [7-11], organic vapor [12-14], hazardous gas [15-19], DNA sequences [20-22], and multiple analytes [23]. Metallic nanowires have also been reported to serve as catalysts in fuel cells [24-28], and solar cells [29-31]. In the field of electronics and devices, due to its excellent conductivity and 1D wire-shape, metallic nanowires have great potential to facilitate device miniturization. In addition, nanowires bonding and joining techniques are also necesssary for device integration, which are being developed through a veriety of approaches including welding, soldering, adhesive coating, diffusion bonding, laser irradiation, and electron/ion beam deposition [32-37].

Various nanowire fabrication methods have been developed. Chemical vapor deposition (CVD), Vapor-Liquid-Solid (VLS) techniques, electroless deposition, electroplating using nanoporous templates, and surfactant assisted chemical reduction methods are the commonly used method for synthesizing nanowires [38-41]. Among these methods, the template-directed method using electroplating is among the most widely employed [42-44]. However, due to the restrinction of the pore spaces in the template, the production yield might be limited. In addition, removing the templates such as track-etched polycarbonate (PC) might involve using toxic organic solvent, and removing anodic alumina membranes (AAO) template using basic solution might cause damage to the as-synthesized metal nanowires [38]. On the other hand, chemical reduction method has the advantages, including no need to remove the template, low cost, and potential for scale up. The ability to control the size and shape of the nanostructures while producing large amount will enable many possibilities to design the nanostructures for nanofabrication and manufacturing.

Tin-Indium (Sn-In) alloy is often used as a lead free solder in the electronic industries as low melting temepratrue solder, which has a melting temperature as low as $118{ }^{\circ} \mathrm{C}$ at its eutectic 
composition ( $\left.\mathrm{Sn} / \mathrm{In} \mathrm{48/52)} \mathrm{[45].} \mathrm{In} \mathrm{addition,} \mathrm{intermetallic} \mathrm{compound} \mathrm{(} \mathrm{InSn}_{4}\right)$ has reported as a potential anode material for Li-Ion battery due to the advantage of combining the cyclic stability of Sn-based electrode and softness of In in accommodating the volumetric change caused by the alloying/dealloying of Sn with Li [46]. Fundamentally, Sn-In binary system has a wide range of compositions that possess different intermetallic compound formations, and thus, it will be interesting to investigate their structure formation at the nanoscale under various synthetic conditions. There has been limited work on the synthesis of Sn/In nanoparticles or nanowires. For example, chemical reduction methods have been used to synthesize $\mathrm{Sn} / \mathrm{In}$ nanoparticles [47] or $\mathrm{In}_{3} \mathrm{Sn}$ nanowires [48]; a solution dispersion method has also been reported to synthesize $\mathrm{Sn} / \mathrm{In}$ nanoparticles [49].

In this study, a one step surfactant-assisted low temperature aqueous phase synthesis of $\mathrm{Sn} / \mathrm{In}$ nanowire was presented. Parameters such as stirring speed, reducing agent injection rate, and elemental composition were studied in controlling the diameter and length of the $\mathrm{Sn} / \mathrm{In}$ nanowires. The morphology, crystalline structure, and thermal properties of the nanowires were examined. Finally, a mechanism of the nanowire growth under different synthetic conditions was proposed.

\section{Material and Methods}

\subsection{Materials and Chemicals}

Sodium dodecyl sulfate (SDS) (85\%) and ethanol (anhydrous) were purchased from Fisher Scientific. Tin (II) sulfate $\left(\mathrm{SnSO}_{4}, 99 \%\right)$, indium chloride $\left(\mathrm{InCl}_{3}, 99.995 \%\right)$ and sodium borohydride $\left(\mathrm{NaBH}_{4}, 99 \%\right)$ were purchased from Acros Organics. Hydrochloric acid $(\mathrm{HCl}$, 36.5\%-38\%) was obtained from VWR scientific. DI water was obtained from a Barnstead Nanopure water purification system. All materials were used without further purification.

\subsection{Synthesis of $\mathrm{Sn} / \mathrm{In}$ Nanowires}

A one-step surfactant-assisted chemical reduction method has been used for the synthesis of $\mathrm{Sn} / \mathrm{In}$ nanoparticles [47]. In this work, a similar method was used to synthesize Sn/In nanowires, but in a low temperature contition (ice bath condition, about $0-2{ }^{\circ} \mathrm{C}$ ). First, SDS was added into DI water to form a $8 \mathrm{mM}$ solution. The $\mathrm{pH}$ was adjusted to $\sim 2.5$ by $\mathrm{HCl}$ to prevent the hydrolysis of $\mathrm{SnSO}_{4}$ and $\mathrm{InCl}_{3}$. After $\mathrm{SnSO}_{4}$ and $\mathrm{InCl}_{3}$ were dissolved in the solution, an excess amount of 
$\mathrm{NaBH}_{4}$ dissolved in $10 \mathrm{ml}$ DI water was added into the system through a syringe pump (singlesyringe infusion pump, KDS LEGATO 110, Kd Scientific), with different injection times (5 min, $15 \mathrm{~min}$, and $25 \mathrm{~min})$ at a constant speed $(120 \mathrm{ml} / \mathrm{h}, 40 \mathrm{ml} / \mathrm{h}$, and $24 \mathrm{ml} / \mathrm{h}$, respectively). The reaction was kept in the ice bath with constant stirring (100 rpm or $300 \mathrm{rpm}$ ) for $30 \mathrm{~min}$. Gray/black precipitation was observed after the reaction finished. The resulting samples were centrifuged (5804 Centrifuge, Eppendorf) at 7000 RPM and washed 3 times with DI water and 3 times with ethanol through dispersion and centrifuge cycles. After the washing steps, the assynthesized Sn/In nanowires were stored in ethanol.

\subsection{Instruments and Characterization}

The morphology and elemental composition of the as-synthesized Sn/In nanowires were characterized with a scanning electron microscope (SEM) and energy dispersive X-ray spectrometer (EDS) on a field emission-scanning electron microscope (JEOL-7401F), and high resolution transmission electron microscopy (HRTEM) together with selected area electron diffraction (SAED) on a transmission electron microscope (JEOL JEM 2100F). The crystal structure of the nanowires was identified by powder x-ray diffraction (XRD) analysis using a BRUKER AXS D5005 X-ray diffractometer (Cu K $\alpha$ radiation, $\lambda=1.540598 \AA$ ). A TA Instrument Q 100 was used for differential scanning calorimetry (DSC) analysis with a heating rate of $10{ }^{\circ} \mathrm{C} / \mathrm{min}$, scanned from $50{ }^{\circ} \mathrm{C}$ to $250{ }^{\circ} \mathrm{C}$.

\section{Results and Discussion}

\subsection{Effect of stirring speed}

Two stirring speeds of $100 \mathrm{rpm}$ and $300 \mathrm{rpm}$ were used in the present work to investigate the stirring speed effect on the formation of $\mathrm{Sn} / \mathrm{In}$ nanowires. Both of the samples were synthesized with a $\mathrm{NaBH}_{4}$ injection time of $25 \mathrm{~min}$ and $\mathrm{Sn} / \mathrm{In}$ starting ratio of 70/30 (weight ratio). The resulting In concentrations exaimined with EDS are 20\% (weight\%) In for both samples. Fig. 1a and 1d show the size and morphology of the Sn/In nanowires that were formed with the two stirring speeds. It can be seen that with both stirring speeds, rather uniform nanowires were formed, even though a very small amount of rod shaped structures (rod defined as length/diameter aspect ratio $\leq 10$ ) can also be observed in the $100 \mathrm{rpm}$ specimen (1a). Two representative nanowires that were formed under the two conditions in Fig. $1 b$ and 1e showed 
that both the nanowires have a similar diameter $(70 \mathrm{~nm}$ and $68 \mathrm{~nm})$. However, the nanowires that were formed with $100 \mathrm{rpm}$ stirring speed have a longer length of $\sim 2 \mu \mathrm{m}$ and larger size distribution, whereas the nanowires formed with $300 \mathrm{rpm}$ were only about $1.1 \mu \mathrm{m}$ in length. The size distribution in Fig. 1c and 1f showed that the size of the nanowires with $100 \mathrm{rpm}$ ranged from 1.4 to $2.6 \mu \mathrm{m}$ in length, whereas the nanowires formed with $300 \mathrm{rpm}$ ranged mainly from 0.9 to $1.4 \mu \mathrm{m}$ in length. It is clear that with higher stirring speed, the nanowires formed tend to be shorter; however, the diameters of the nanowires remained the same. This observation indicated that, after the initial nucleation stage, the nanowires only grew along one direction, and the stirring speed would not change the diameter of the nanowires, but can effectively control the length while they grow.
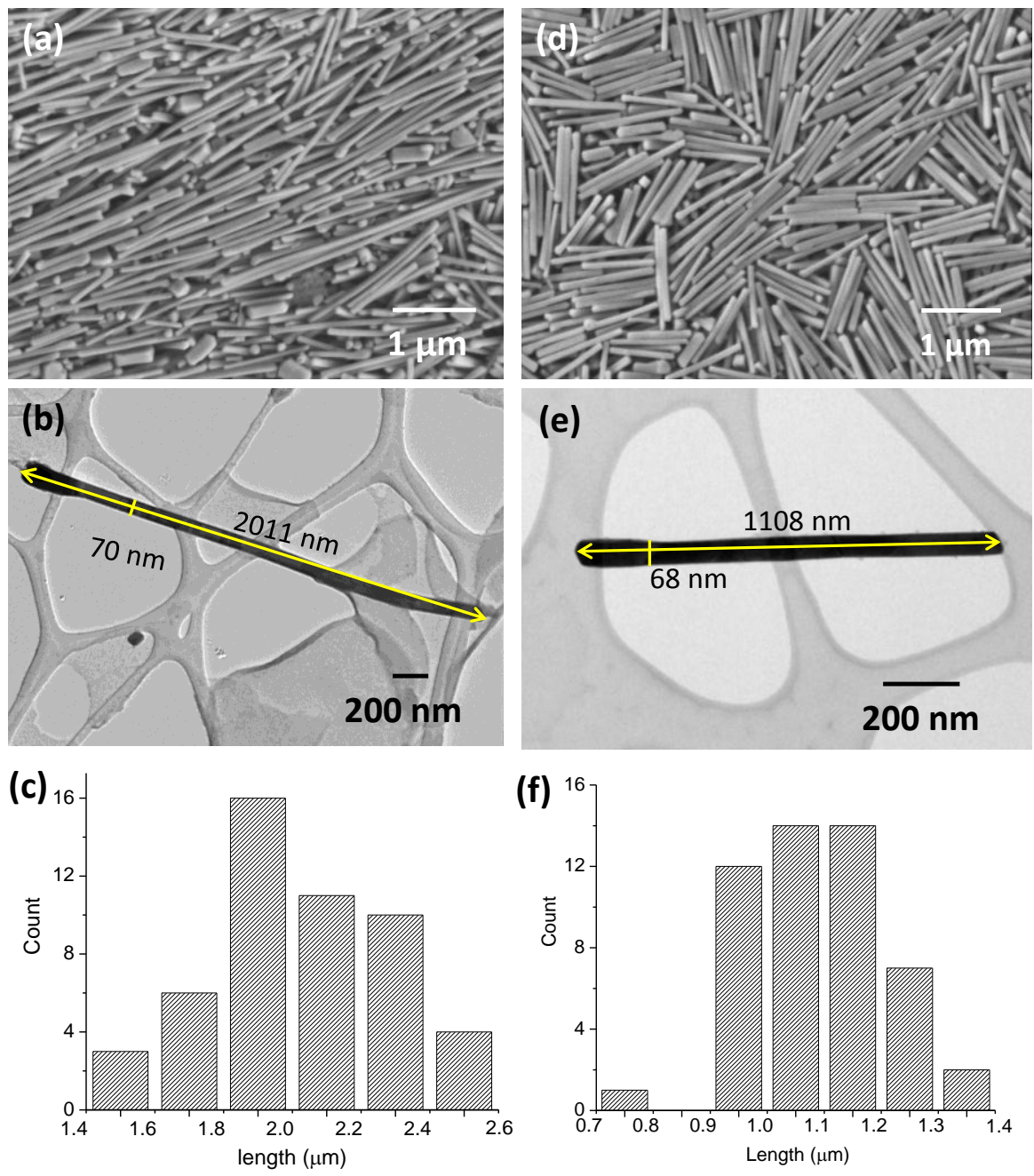

Fig. 1: Effect of stirring speed on the formation of Sn/In nanowires (20\% In): SEM images of nanowires that were formed with $100 \mathrm{rpm}$ (a) and $300 \mathrm{rpm}$ (d), TEM images of typical nanowires that were formed with $100 \mathrm{rpm}$ (b) and $300 \mathrm{rpm}$ (e), and size distribution (length) of nanowires that were formed with $100 \mathrm{rpm}$ (c) and $300 \mathrm{rpm}$ (f). 


\subsection{Effect of injection rate of reducing agent}

The injection rate of sodium borohydride $\left(\mathrm{NaBH}_{4}\right)$ has a critical effect on the formation of the nanowires. Controlled experiments were carried out to investigate the influence of $\mathrm{NaBH}_{4}$ injection time on the synthesis of the Sn/In nanowires with the same composition of $20 \%$ In. In the present work, $\mathrm{NaBH}_{4}$ was used as the reducing agent, which was dispersed in the solution through a programmable syringe pump at a constant speed. Under the stirring speed of $100 \mathrm{rpm}$, $10 \mathrm{~mL}$ of $\mathrm{NaBH}_{4}(0.45 \mathrm{M})$ with injection time of $5 \mathrm{~min}, 15 \mathrm{~min}$, and $25 \mathrm{~min}$ were tested, respectively. The corresponding injection rates are $120 \mathrm{ml} / \mathrm{h}, 40 \mathrm{ml} / \mathrm{h}$, and $24 \mathrm{ml} / \mathrm{h}$. It can be observed from the SEM images in Fig. 2a-c that the longer the $\mathrm{NaBH}_{4}$ injection time was, the longer nanowires were produced. However, the nanowires formed had almost the same diameter of $\sim 70 \mathrm{~nm}$ for all the three $\mathrm{NaBH}_{4}$ injection times that were used. Fig. $2 \mathrm{~d}$ shows the average length of the nanowires obtained at the different $\mathrm{NaBH}_{4}$ injection times, and the nanowire length changed from $0.55 \mu \mathrm{m}(5 \mathrm{~min})$ to $0.89 \mu \mathrm{m}(15 \mathrm{~min})$, and finally reached $2.2 \mu \mathrm{m}(25 \mathrm{~min})$, which were about 4 times longer than the samples formed at $5 \mathrm{~min}$ injection time. The results above suggested that the length of the nanowires strongly depends on the reducing agent injection rate.
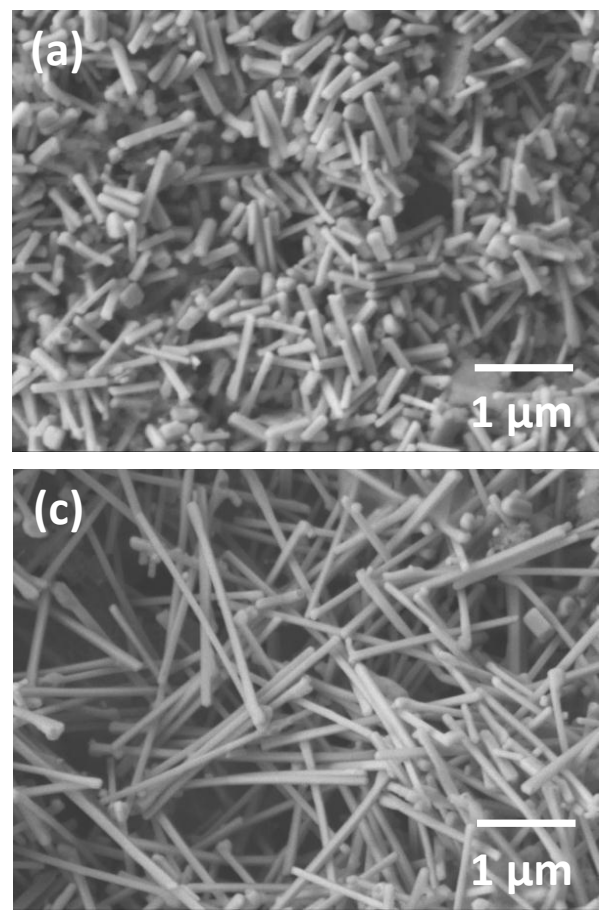

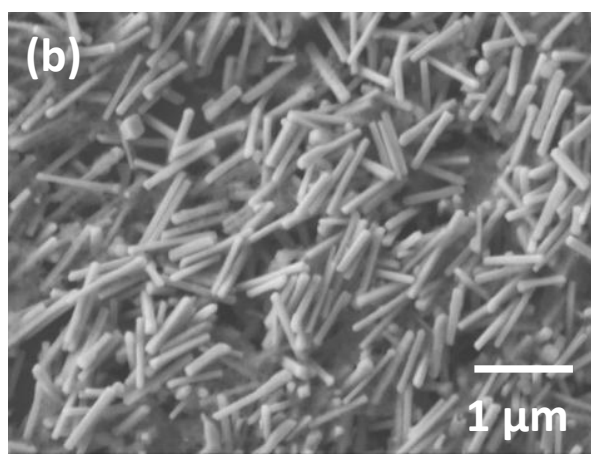

(d)

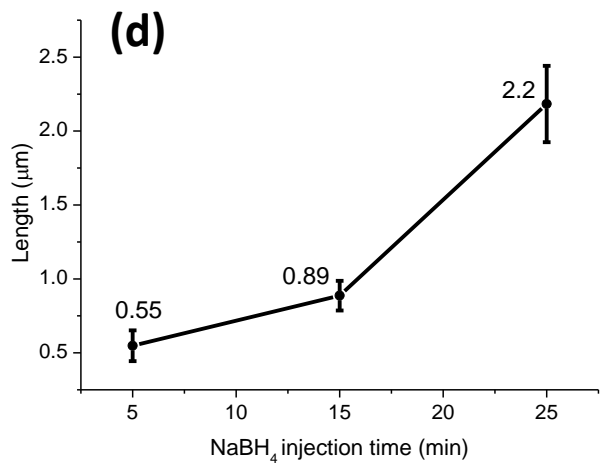

Fig. 2: Effect of reducing agent $\mathrm{NaBH}_{4}$ injection time on nanowire growth: (a) $5 \mathrm{~min}$, (b) $15 \mathrm{~min}$, and (c) $25 \mathrm{~min}$. (d) Average length of the nanowires at different $\mathrm{NaBH}_{4}$ injection times. The error bars on the curve indicate the standard deviation of the nanowire length, where $\sim 50$ nanowires were measured for each sample. 


\subsection{Effect of elemental composition}

After investigating the effects of both stirring speed and reducing agent injection rate, elemental composition of $\mathrm{Sn} / \mathrm{In}$ has also been studied to fine tune the morphology of the nanowires formed. Table 1 shows the resulting indium concentration (wt\% In) in the nanowires formed with $300 \mathrm{rpm}$ and 25 min $\mathrm{NaBH}_{4}$ injection time, with varying starting composition of In (wt\%). The In composition in the as-synthesized nanowires increased as the starting In increased; however, the resulting In compositions were significantly lower than the strating In composition values. Fig. 3 also compared the results with a previous study on $\mathrm{Sn} / \mathrm{In}$ nanosolder particles, in which the Sn/In nanosolder particles were synthesized at a similar condition but in room temperature [47]. The resulting elemental compositions of the Sn/In nanoparticles were very close to the starting precursor concentrations (see the blue triagles). The significant devaiation of In composition compared to their starting values in this work, suggesting that In is less likely to precipitate at low temperature such as $0{ }^{\circ} \mathrm{C}$.

Table 1. Starting and resulting concentrations (wt\% In) for the $\mathrm{Sn} / \mathrm{In}$ nanowires

\begin{tabular}{|c|c|}
\hline $\begin{array}{c}\text { Starting Conc. } \\
\text { of In (weight \%) }\end{array}$ & $\begin{array}{c}\text { Resulting Conc. } \\
\text { of In (weight \%) }\end{array}$ \\
\hline 20 & 18 \\
\hline 30 & 20 \\
\hline 40 & 24 \\
\hline 50 & 25 \\
\hline 60 & 31 \\
\hline 70 & 32 \\
\hline 80 & 47 \\
\hline
\end{tabular}




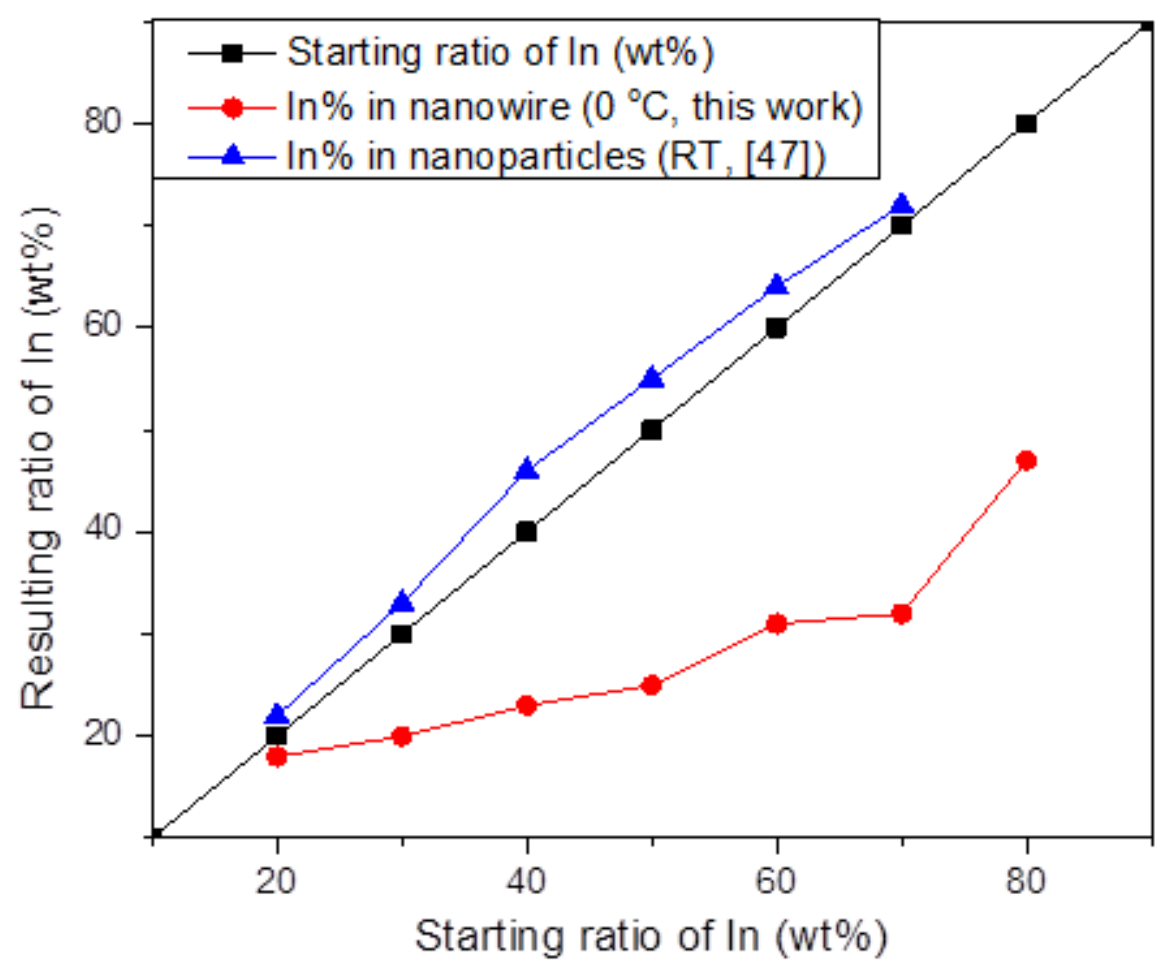

Fig. 3: Resulting In\% in $\mathrm{Sn} / \mathrm{In}$ nanowires (synthesized at $0{ }^{\circ} \mathrm{C}$ ) and nanoparticles (synthesized at room temperature [47]), compared with the starting In ratio in the precursor solutions.

Fig. 4 shows the morphology and length of nanowires that were obtained with different $\mathrm{Sn} / \mathrm{In}$ elemental compositions. The starting ratios of In in the precursors were $30 \%, 70 \%, 80 \%$, and the elemental compositions from the EDS analysis were 20\%, 32\%, and 47\% In, respectively. It can be observed that as the In ratio increased in the samples, the nanowires became shorter. However, the TEM images in Fig. 4b, 4d and 4f showed that the diameters of the nanowires with different In ratios almost stayed at the same value of around $70 \mathrm{~nm}$, which was the same dimeter of the nanowires obtained with different stirring speeds and reducing agent injection rates. 


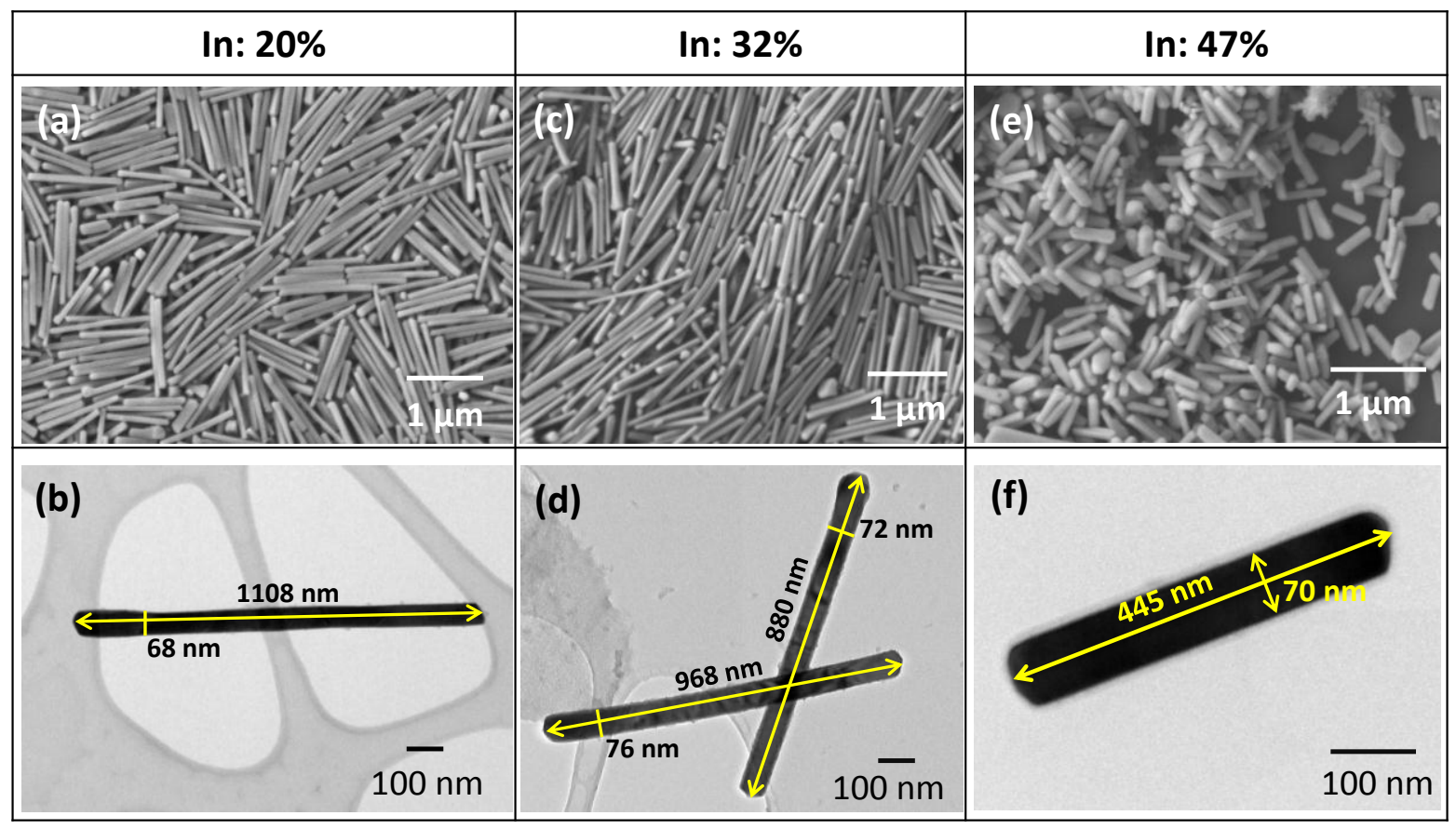

Fig. 4: SEM and TEM images of Sn/In nanowires that were formed at different $\mathrm{Sn} / \mathrm{In}$ elemental compositions: (a) and (b) $20 \%$ In; (c) and (d) $32 \%$ In; (e) and (f) $47 \%$ In.

The average length of the nanowires obtained with $100 \mathrm{rpm}$ and $300 \mathrm{rpm}$ and different In ratios was summarized in Fig. 5. The average length with error bars were obtained by measuring at least 50 nanowires for each sample. The error bars of the samples at $47 \%$ In were smaller than the symbles and thus were not shown. It can be observed that under both stirring speeds, the length of the nanowires decreased as the In ratio increased. Consistent with the observations in section 3.1, the nanowires obtained at $300 \mathrm{rpm}$ have a shorter length than the nanowires obtained at $100 \mathrm{rpm}$ with the same ratio. Also, the diameters of the nanowires at all conditions remained the same of around $70 \mathrm{~nm}$, indicating that the nanowires are growing along one direction since the diameters of the nanowires almost remained the same under different parameters. 


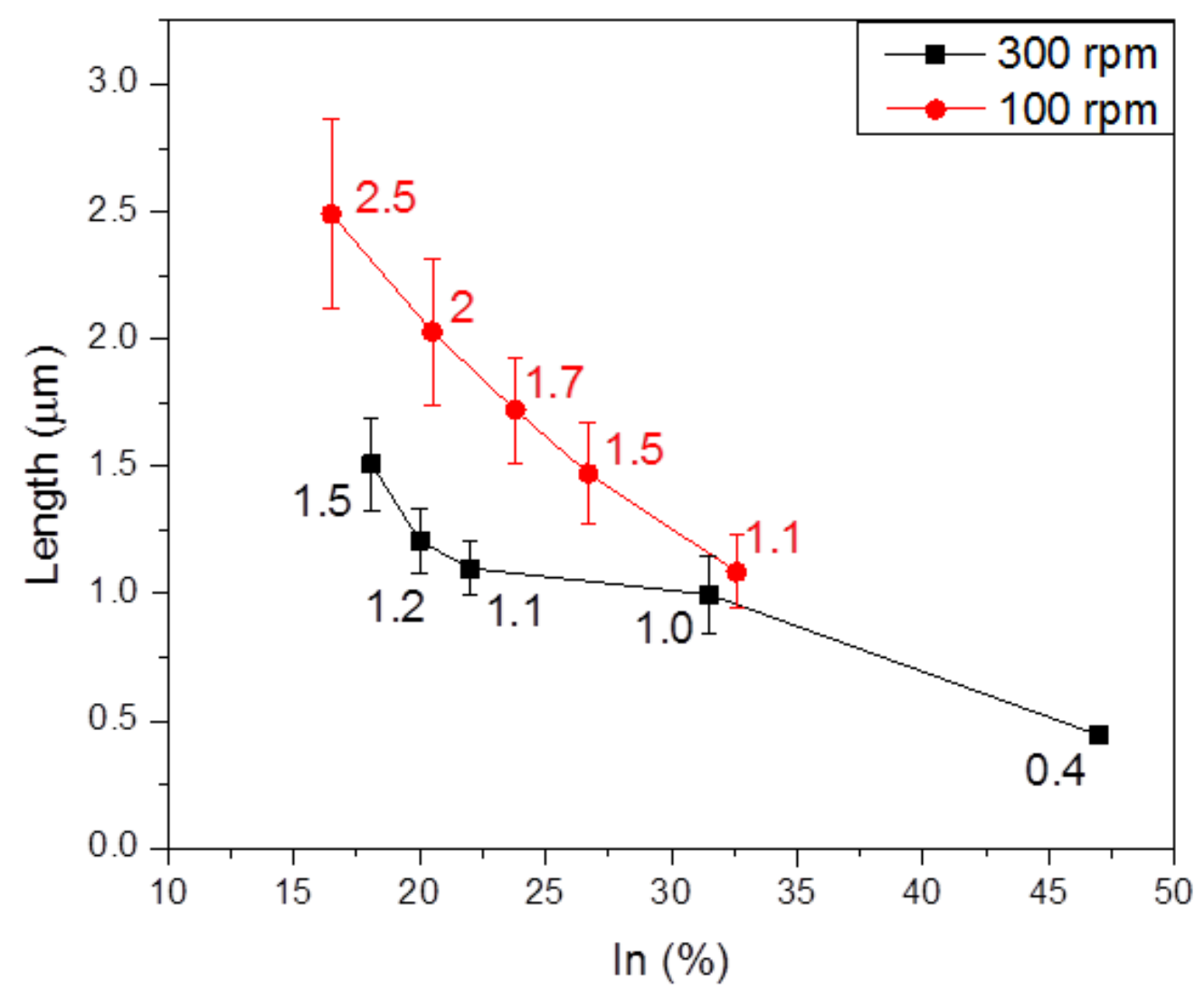

Fig. 5: Average length of Sn/In nanowires with different indium concentrations that were synthesized at $100 \mathrm{rpm}$ and $300 \mathrm{rpm}$.

\subsection{Structural analysis of $\mathrm{Sn} / \mathrm{In}$ nanowires}

The crystal structure of the Sn/In nanowires was analysized by XRD. Fig. 6a-b show the XRD spectra of the nanowires that were discussed in section 3.1, which were synthesized with $100 \mathrm{rpm}$ and $300 \mathrm{rpm}$, respectively, and the $\mathrm{NaBH}_{4}$ injection time of $25 \mathrm{~min}$ for both samples, with the resulting In ratio of $20 \%$ for both samples. Since the elemental ratio of Sn:In is approximately 4:1, an alloy of $\mathrm{InSn}_{4}$ is expected from this composition. It can be seen that the XRD spectra of both samples have similar patterns. Both specimens consist mainly of $\mathrm{InSn}_{4}$, but a small amount of Sn can also be observed. The XRD results suggested that with both stirring speeds, the produced nanowires have the same crystal structures, and the only difference is the length of the nanowires. The crystal structure of the specimens at other In concentrations are also examined. When In concentration was lower than $20 \%$, the crystal structures that were found in the XRD spectra are still mostly InSn4 and Sn; however, the Sn peak was found to be higher with increased Sn ratio, indicating higher amount of Sn, which is consistent with the bulk Sn-In phase 
diagram [45]. When the In concentration was above 20\%, in addition to $\mathrm{InSn}_{4}$ and $\mathrm{Sn}$ peaks, a small peak at $32.9^{\circ}$ that contributed from In (101) also showed up, as shown in Fig. 6c for sample $23 \%$ In, indicating that In phase may also be formed during the synthesis as the In concentration increased.

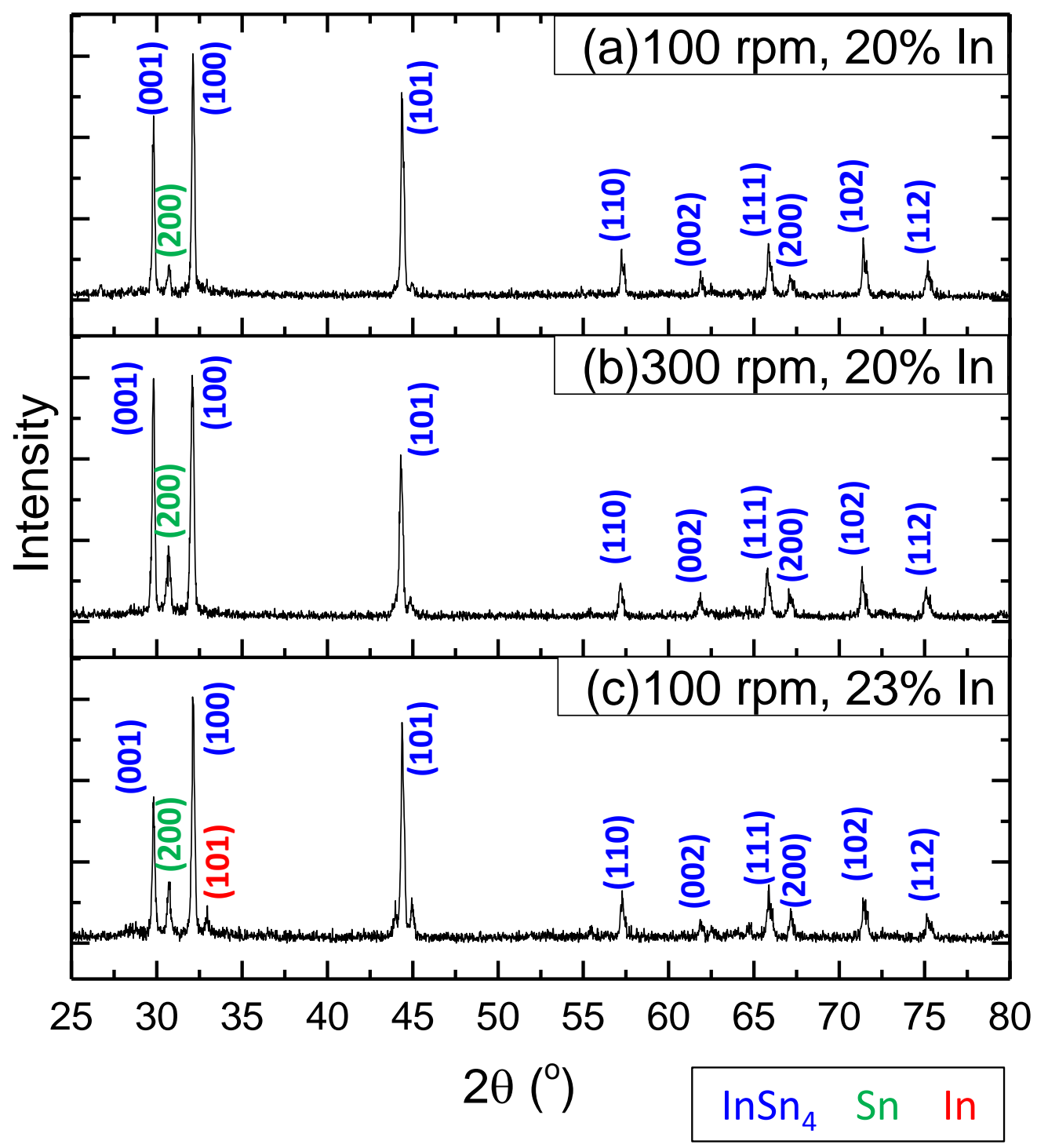

Fig. 6: XRD spectra of 20\% In nanowires synthesized with (a) $100 \mathrm{rpm}$ and (b) $300 \mathrm{rpm}$, and (c) 23\% In nanowires with $100 \mathrm{rpm}$.

The as-synthesized Sn/In nanowires were also subjected to TEM analysis. Fig. 7 shows a typical nanowire that was found in the specimen synthesized with $100 \mathrm{rpm}$ with In concentration of 20\%. From Fig. 7a it can be measured that the nanowire is about $1.08 \mu \mathrm{m}$ in length and $70 \mathrm{~nm}$ 
in width. A high-resolution TEM (HRTEM) image of the zoomed in area of the nanowire was shown in Fig. 7b, which indicated the area of the nanowire is single crystal. About 2-3 nm amorphous oxide layer can also be observed on the surface of the nanowire, which is consistent with previous results on $\mathrm{Sn}$ nanorods prepared by a similar chemical reduction method [50] or Sn-based nanowires synthesized by electrodeposition method [51]. The interplaner spacing was measured to be $3.064 \AA$. The selected area electron diffraction (SAED) pattern of the nanowire is shown in Fig. 7c, which can be indexed as either $\mathrm{InSn}_{4}$ [0110] or $\mathrm{Sn}$ [103]. However, the measured d spacing from HRTEM image confirms that it is $\mathrm{InSn}_{4}$. Therefore, the phase and structure of the nanowire is confirmed as $\mathrm{InSn}_{4}$. The growth direction of the crystalline structure is marked in the HRTEM image of Fig. 7(b) by the white line with arrow. This direction is aligned with the (0001) plane of $\mathrm{InSn}_{4}$ hexagonal structure. With the surfactant employed for the synthesis, the surface energy of (0001) plane or facet is thermodynamically preferred, in order to minimize the total surface energy, leading to elongated rod/wire as the resulting shape for the InSn4 crystal.
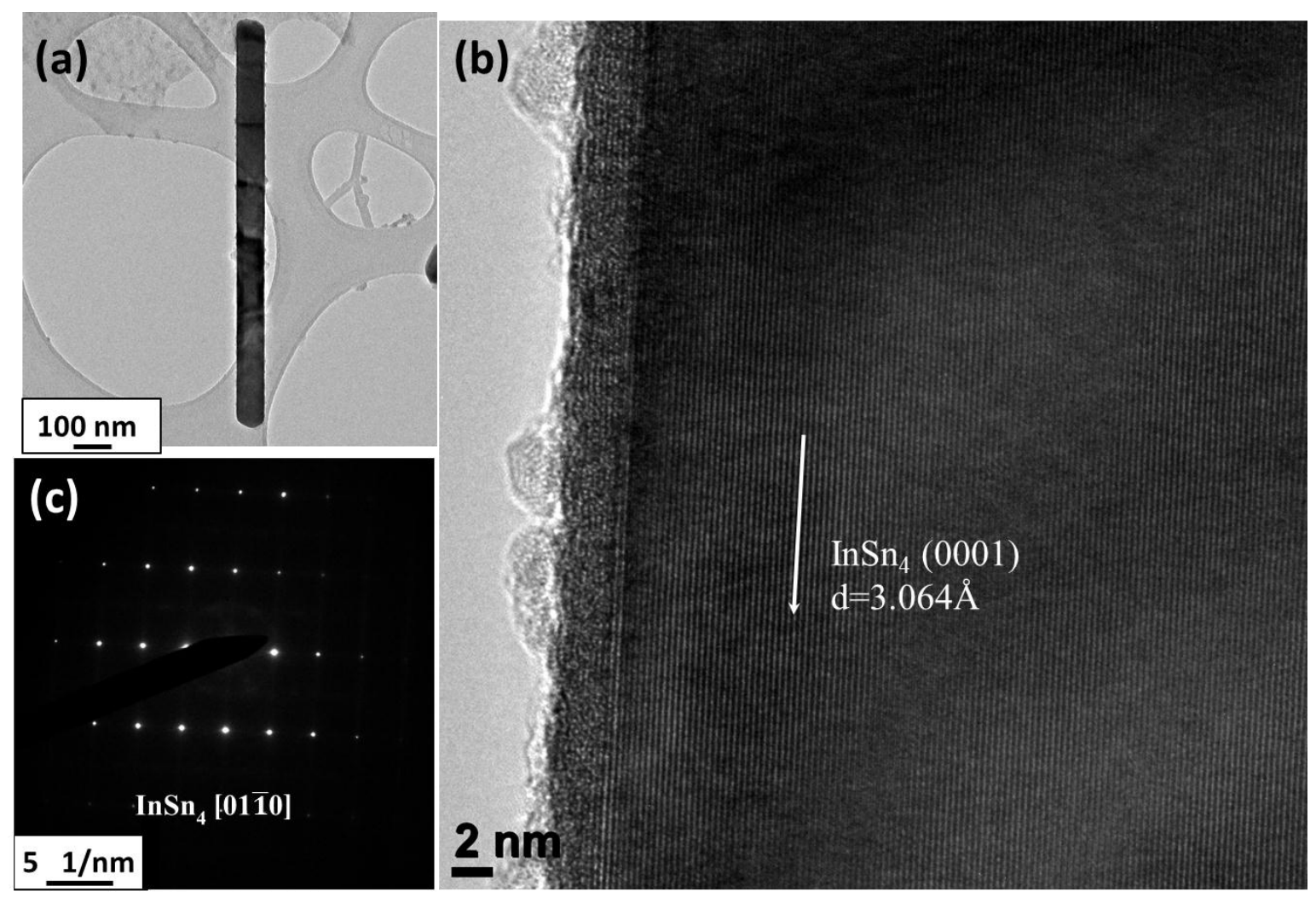

Fig. 7: TEM analysis of a $\mathrm{InSn}_{4}$ nanowire synthesized under $100 \mathrm{rpm}$ with In $20 \%$, (a) TEM image, (b) HRTEM image, and (c) SAED pattern. 
Sn nanowire was also found in this specimen. The nanowire in Fig. 8 has a similar length $(1.1 \mu \mathrm{m})$ and width $(70 \mathrm{~nm})$ as the nanowire showed in Fig. 7. The crystal structure that was indexed from the SAED pattern in Fig. 8(b) revealed that the nanowire is Sn. The results from TEM measurements confirmed the $\mathrm{Sn}$ and $\mathrm{InSn}_{4}$ structures that were observed from XRD (Fig. 6a). However, no In phase was observed from the TEM analysis of sample $23 \%$ In, which may be due to the limited number of nanowires that were examined under TEM.
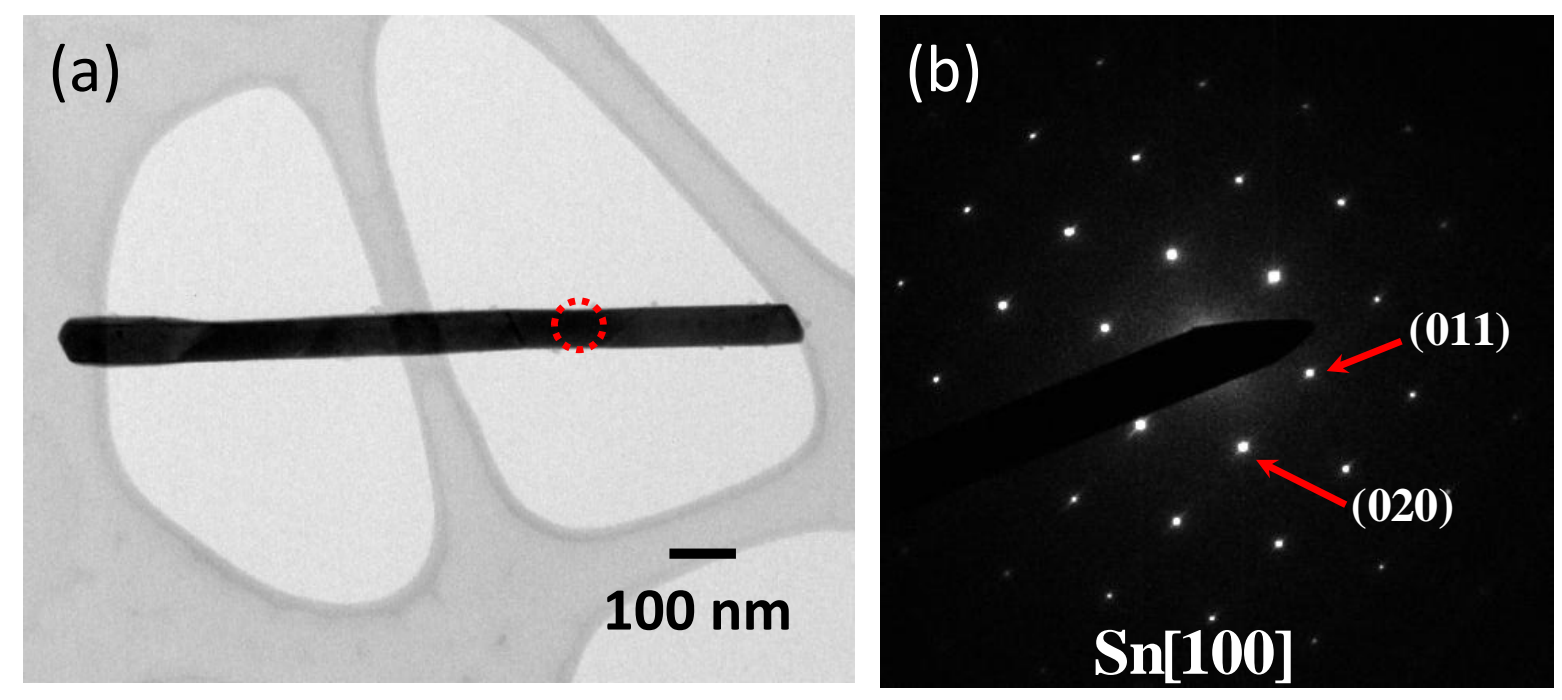

Fig. 8: TEM analysis of a Sn nanowire synthesized under $100 \mathrm{rpm}$ with $20 \% \mathrm{In}$, (a) TEM image and (b) SAED taken from the area encircled by the red dash line as shown in Fig. 8(a).

In addition to the $\mathrm{InSn}_{4}$ nanowires and $\mathrm{Sn}$ nanowires shown in Fig. 7 and 8, another type of nanowires was also observed. Fig. 9a shows the TEM images of some nanowires that were synthesized at $300 \mathrm{rpm}$ with $32 \%$ of In. The SAED pattern in Fig. 9b shows that both Sn and $\mathrm{InSn}_{4}$ phases were observed from the tip of the same nanowire (horizontal in the figure). The overlapped reciprocal lattices indicate the expitaxial relationship between $\mathrm{Sn}(011)$ and $\mathrm{InSn}_{4}$ (1000) or $(1 \overline{1} 00)$. 

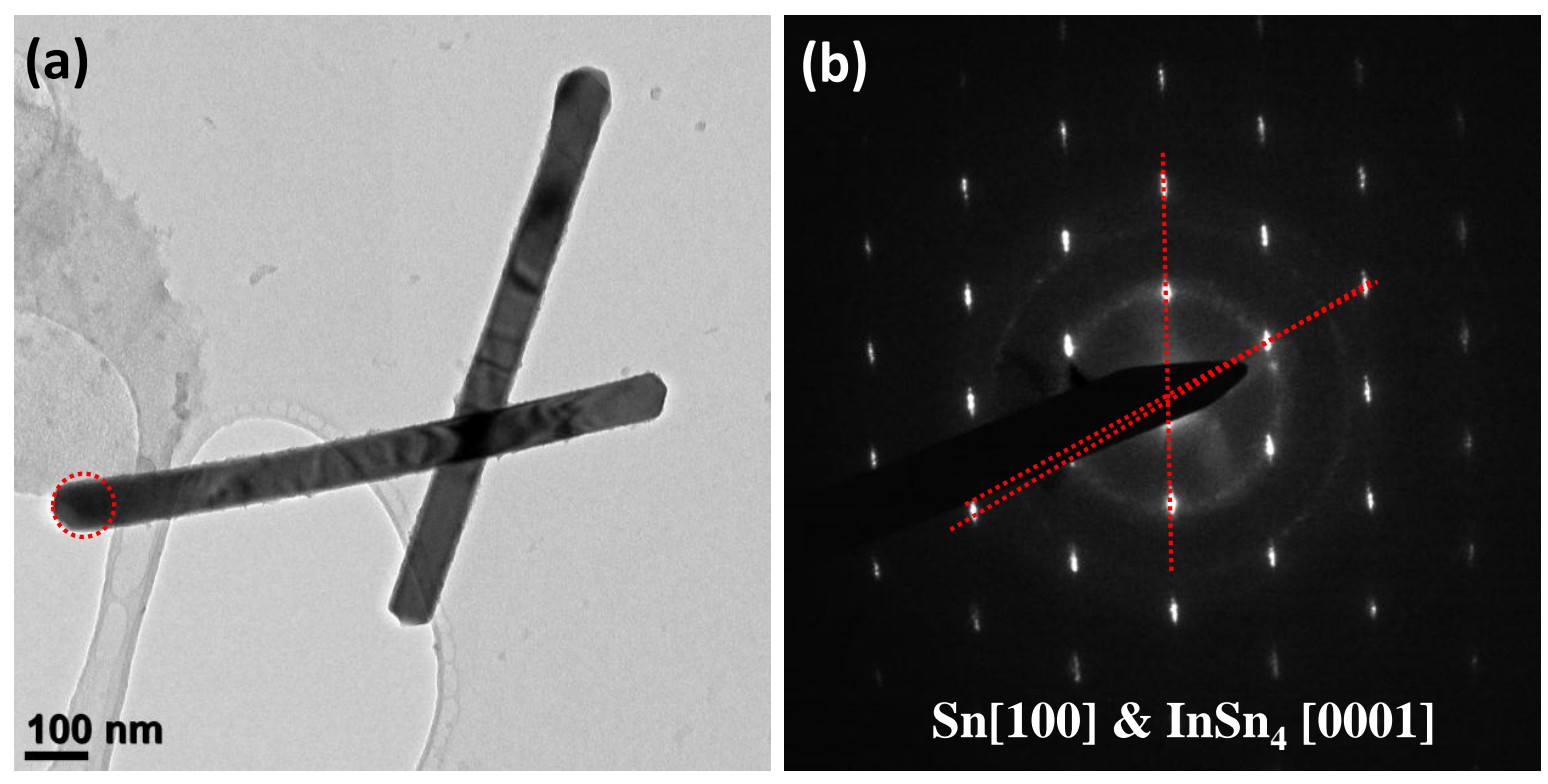

Fig. 9: TEM analysis of Sn/In nanowires synthesized under $300 \mathrm{rpm}$ with $32 \% \mathrm{In}$, (a) TEM image and (b) SAED taken from the area encircled by the red dash line as shown in Fig. 9(a).

\subsection{Thermal properties of Sn/In nanowires}

The thermal properties of the $\mathrm{Sn} / \mathrm{In}$ nanowires discussed in the previous sections were measured by DSC. Fig. 10a-b show the DSC plots of the nanowires that were synthesized at 100 rpm and $300 \mathrm{rpm}$, respectively, with the reducing agent $\mathrm{NaBH}_{4}$ injection time of $25 \mathrm{~min}$. Both of the specimens have the In composition of $20 \%$. For both DSC curves, two peaks can be observed: a major peak at around $205 / 206{ }^{\circ} \mathrm{C}$ and a minor peak at $117.8{ }^{\circ} \mathrm{C}$. The peak at around $205{ }^{\circ} \mathrm{C}$ was contributed from the liquidus of $\mathrm{Sn} / \mathrm{In}$ alloy at about $20 \%$ In composition, while the minor peak appeared at $117.8{ }^{\circ} \mathrm{C}$ should be contributed from the metastable eutectic melting because no In $3 \mathrm{Sn}$ was observed in the nanowires. DSC measurement has also been performed on the specimens with different In concentrations. When the In composition was lower than $20 \%$, such as $18 \%$, the DSC results are similar to the ones of $20 \%$ In. While at In compositions higher than $20 \%$, e.g., $23 \%$ In as shown in Fig. 10c, the minor peak occurred at around $117.5{ }^{\circ} \mathrm{C}$ is slightly bigger, indicating more In in the metastable eutectic melting; after that, a major peak showed up at $209.7^{\circ} \mathrm{C}$, indicating the liquidus of $\mathrm{Sn} / \mathrm{In}$ alloy, which is similar to the $20 \%$ In sample. 


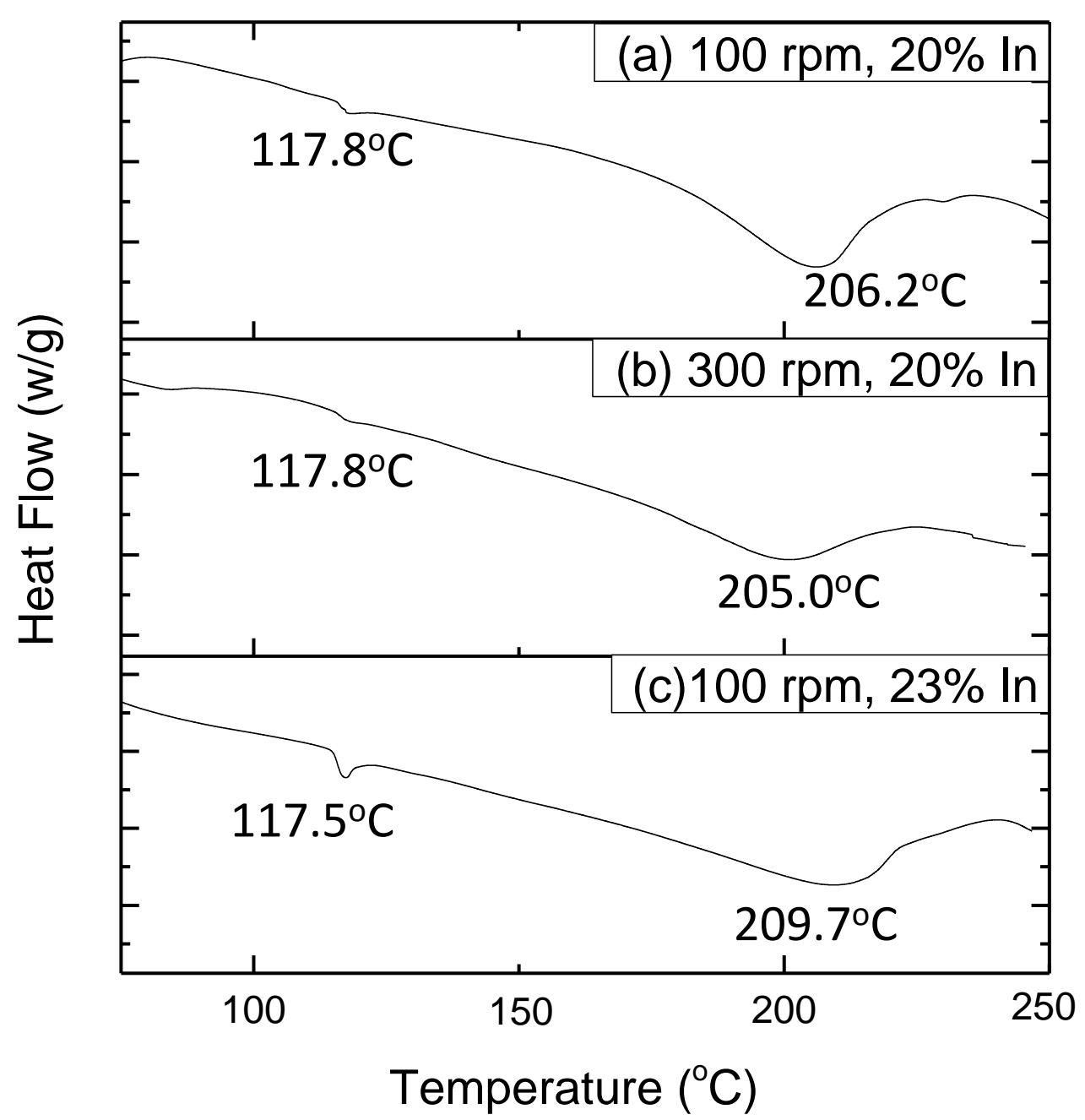

Fig. 10: DSC curves of 20\% In nanowires synthesized with (a) $100 \mathrm{rpm}$ and (b) $300 \mathrm{rpm}$, and (c) 23\% In nanowires synthesized with $100 \mathrm{rpm}$.

\subsection{Proposed mechanism of nanowire formation and growth}

From the above experimental observations, the $\mathrm{Sn} / \mathrm{In}$ nanowires are mostly monodispeared at each synthetic conditions. It indicated that, after the intial nucleation stage, no nucleation occurred during the nanowire growth stage. It can be assumed that the nucleation rate is significantly reduced as the nucleation progresses, and then nanowire growth will be the main process that takes place. Therefore, the finial product density is determined mostly by the supply rate of the reacting agent and/or the growth rate of the generated nuclei. A proposed mechanism is shown in Fig. 11. The examination of the nanowires that were formed with different reducing agent injection times showed that the nanowires are monodispersed under different $\mathrm{NaBH}_{4}$ 
injection times. As the injection time of the reducing agent $\mathrm{NaBH}_{4}$ extended, i.e. the rate of injection ( $\mathrm{R}_{\mathrm{NaBH}}$ ) decreased, the length of the nanowires became greater. The results confirmed that nucleation took place at the early statge of the reaction; less seeds were formed with longer $\mathrm{NaBH}_{4}$ injection time. Hence, more precusors remaining in the solution were involed in the nanowire growth, leading to the formation of longer nanowires.

In the case of different stirring speeds, higher stirring speed led to better mixing, with more seeds formed at the early stage, resulting in shorter nanowires in the final product. When the stirring speed was lower, less seeds were formed in the early stage, therefore leading to longer nanowire formation. Also, the length of the nanowires has a wider distribution when using lower stirring speed. This may result from less efficient mixing at lower stirring speed. When the stirring speed was too low, no good quality nanowire was formed.

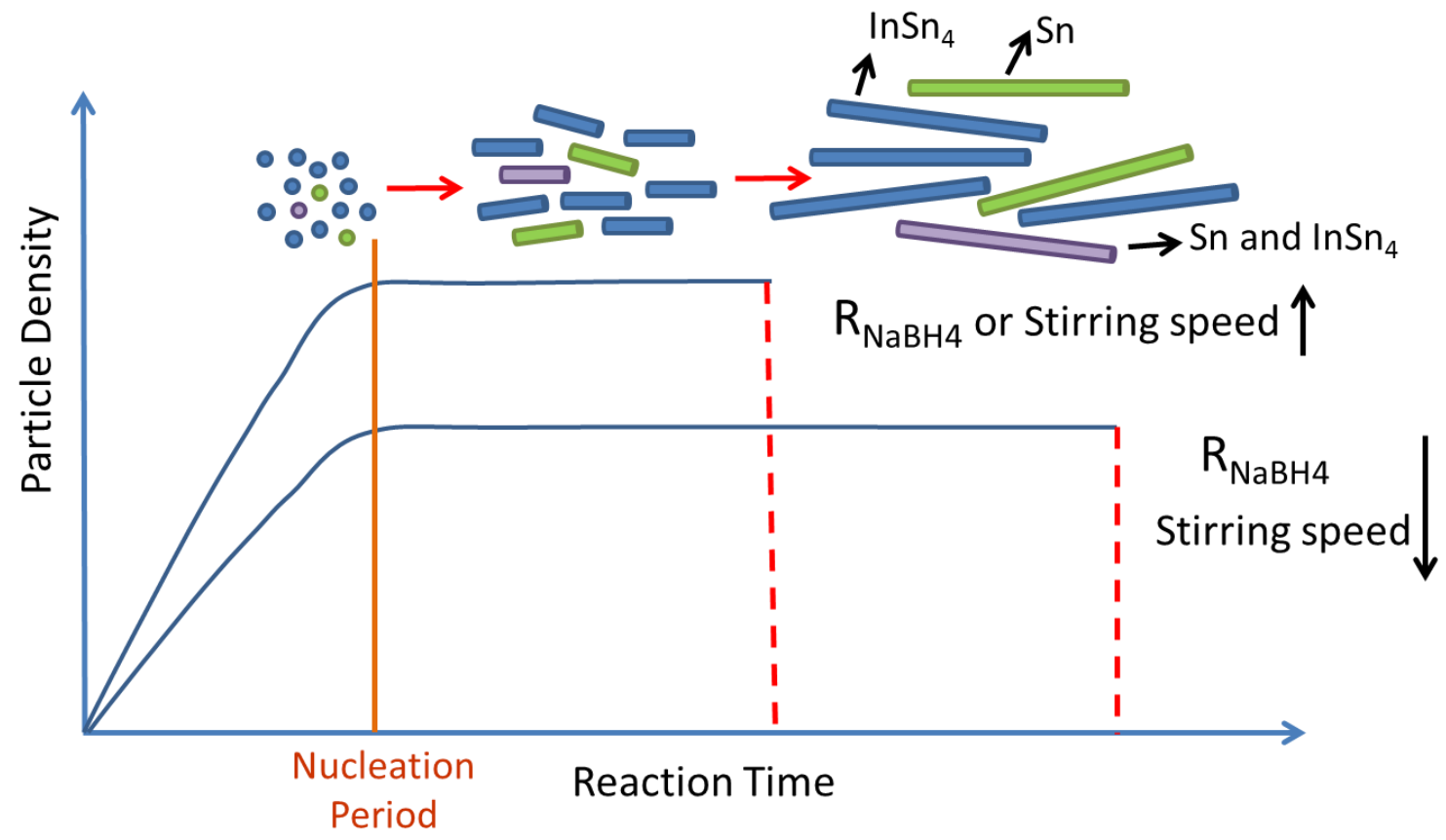

Fig. 11: Proposed nucleation mechanism for $\mathrm{Sn} / \mathrm{In}$ nanowire growth.

From the previous discussion, it can be found that when the starting In ratio was low ( 20\%), the In ratio in the resulting nanowires was well maintained, as indicated in Table 1. However, when the starting In ratio increased, the In composition in the resulting nanowires was 
significantly lower than the starting ratio. This observation indicated that In is less likely to precipitate in the nanowire synthesis process, even at a relatively high starting In composition of $80 \%$. Also, from the XRD results, $\mathrm{Sn}, \mathrm{InSn}_{4}$, and In were the three crystal structures that can be observed for compositions at $23 \%$ In or above; however, the amount of In was small. Also, no $\mathrm{In}_{3} \mathrm{Sn}$ was observed for these compositions. This metastable (or non-equilibrium) phase behavior is similar to the $\mathrm{Sn} / \mathrm{In}$ nanoparticle formation process that was published before [47]. At room temperature or low temperature, $\operatorname{In}_{3} \mathrm{Sn}$ phase normally is not formed through the chemical reduction method. In this nanowire synthesis process, $\mathrm{InSn}_{4}$ is a preferred phase to form for all the compositions observed. For compositions with $23 \%$ In or higher, most Sn reacted with In for the formation of $\mathrm{InSn}_{4}$, and only a small amount of excess In may precipitate during the nanowire formation, which was confirmed from XRD measurements however was no observed by TEM. In addition, the length of the nanowires that were synthesized is also related to the $\mathrm{Sn} / \mathrm{In}$ ratios. The higher the In ratio is, the shorter the nanowires were observed. With higher In ratio, more InSn4 nuclei may be formed during the nucleation step, therefore, leaving less amount of Sn to supply the growth of nanowire.

\section{Conclusions}

A one-step aqueous solution based chemical reduction method was successfully used to synthesize $\mathrm{Sn} / \mathrm{In}$ nanowires at low temperature. Uniform nanowires with different lengths can be obtained through this method, by controlling the parameters such as stirring speed, reducing agent injection time, and elemental composition, while the diameters of the nanowires keeping roughly the same. The as-synthesized nanowires were composed mainly of $\mathrm{InSn}_{4}$ and $\mathrm{Sn}$; however, no In3Sn phase was observed. Thermal property measurements showed that the nanowires started to melt at around $118{ }^{\circ} \mathrm{C}$, which indicated that the nanowries can serve as a low melting temperature solder material for flexible electronics, or for the assembly and packaging of electronics or photonics with thermal sensitive mateials or components. The nanowire formation followed a growth-controlled nucleation mechanism. 


\section{Acknowledgements}

We are thankful for the financial support from the National Science Foundation (CMMI1234532). The TEM analysis was carried out in part at the Center for Functional Nanomaterials, Brookhaven National Laboratory, which is supported by the U.S. Department of Energy, Office of Basic Energy Sciences, under Contract No. DE-SC0012704.

\section{References}

[1] Z. M. Wang, ed., “One-dimensional nanostructures”, Vol. 3. Springer Science \& Business Media, 2008.

[2] Y. Xia, P.Yang, Y. Sun, Y. Wu, B. Mayers, B. Gates, Y. Yin, F. Kim, H. Yan. "Onedimensional nanostructures: synthesis, characterization, and applications." Advanced Materials 15, no. 5 (2003): 353-389.

[3] B. Weng, S. Liu, Z. Tang, Y. Xu. "One-dimensional nanostructure based materials for versatile photocatalytic applications." RSC Advances 4, no. 25 (2014): 12685-12700.

[4] A. Kolmakov, M. Moskovits. "Chemical sensing and catalysis by one-dimensional metaloxide nanostructures.” Annu. Rev. Mater. Res. 34 (2004): 151-180.

[5] J. Weber, R. Singhal, S. Zekri, A. Kumar. "One-dimensional nanostructures: fabrication, characterisation and applications.” International Materials Reviews 53 (2013): 235-255.

[6] J. Chen, J. Zhang, M. Wang, Y. Li. "High-temperature hydrogen sensor based on platinum nanoparticle-decorated SiC nanowire device." Sensors and Actuators B: Chemical 201 (2014): 402-406.

[7] Z. Li, C. Leung, F. Gao, Z. Gu, "Effects of Nanowire Length and Surface Roughness on the Electrochemical Sensor Properties of Nafion-Free, Vertically Aligned Pt Nanowire Array Electrodes", Sensors 15, no. 9 (2015): 22473-22489.

[8] Q. Han, P. Ni, Z. Liu, X. Dong, Y. Wang, Z. Li, Z. Liu. "Enhanced hydrogen peroxide sensing by incorporating manganese dioxide nanowire with silver nanoparticles." Electrochemistry Communications 38 (2014): 110-113. 
[9] S. Dong, J. Xi, Y. Wu, H. Liu, C. Fu, H. Liu, F. Xiao. "High loading MnO2 nanowires on graphene paper: facile electrochemical synthesis and use as flexible electrode for tracking hydrogen peroxide secretion in live cells.” Analytica Chimica Acta 853 (2015): 200-206.

[10] Q. Yan, Z. Wang, J. Zhang, H. Peng, X. Chen, H. Hou, C. Liu. "Nickel hydroxide modified silicon nanowires electrode for hydrogen peroxide sensor applications." Electrochimica Acta 61 (2012): 148-153.

[11] X. Qin, H. Wang, Z. Miao, J. Li, Q. Chen. "A novel non-enzyme hydrogen peroxide sensor based on catalytic reduction property of silver nanowires." Talanta 139 (2015): 56-61.

[12] X. Li, J. H. Cho, P. Kurup, Z. Gu, "Novel sensor array based on doped tin oxide nanowires for organic vapor detection." Sensors and Actuators B: Chemical 162 (2012): 251-258.

[13] N. Ramgir, N. Datta, M. Kaur, S. Kailasaganapathi, A. K. Debnath, D. K. Aswal, S. K. Gupta. "Metal oxide nanowires for chemiresistive gas sensors: issues, challenges and prospects." Colloids and Surfaces A: Physicochemical and Engineering Aspects 439 (2013): 101-116.

[14] L. Wang, Y. Kang, X. Liu, S. Zhang, W. Huang, S. Wang. "ZnO nanorod gas sensor for ethanol detection." Sensors and Actuators B: Chemical 162 (2012): 237-243.

[15] X. Li, Y. Wang, Y. Lei, Z. Gu, "Highly sensitive $\mathrm{H}_{2} \mathrm{~S}$ sensor based on template-synthesized CuO nanowires." RSC Advances 2 (2012): 2302-2307.

[16] X. Chen, CKY. Wong, Cadmus A. Yuan, and Guoqi Zhang. "Nanowire-based gas sensors.” Sensors and Actuators B: Chemical 177 (2013): 178-195.

[17] A.Cao, E. J.R. Sudhölter , L. C.P.M. de Smet, "Silicon Nanowire-Based Devices for GasPhase Sensing." Sensors 14, no 1 (2014): 245-271.

[18] ND. Hoa, P. Van Tong, N. Van Duy, T. D. Dao, H. V. Chung, T. Nagao, N. Van Hieu. "Effective decoration of Pd nanoparticles on the surface of SnO 2 nanowires for enhancement of CO gas-sensing performance.” Journal of Hazardous Materials 265 (2014): 124-132.

[19] S. Park, S. An, H. Ko, C. Jin, and Chongmu Lee. "Synthesis of nanograined ZnO nanowires and their enhanced gas sensing properties." ACS Applied Materials \& Interfaces 4, no. 7 (2012): 3650-3656.

[20] P. Xie, Q. Xiong, Y. Fang, Q. Qing, C. M. Lieber. "Local electrical potential detection of DNA by nanowire-nanopore sensors." Nature Nanotechnology 7, no. 2 (2012): 119-125. 
[21] G. Zhang, G. Zhang, J. H. Chua, R. Chee, E. H. Wong, A. Agarwal, K. D. Buddharaju, N. Singh, Z. Gao, N. Balasubramanian. "DNA sensing by silicon nanowire: charge layer distance dependence." Nano Letters 8, no. 4 (2008): 1066-1070.

[22] Z. Gao, A. Agarwal, A. D. Trigg, N. Singh, C. Fang, C. Tung, Y. Fan, K. D. Buddharaju, J. Kong. "Silicon nanowire arrays for label-free detection of DNA." Analytical Chemistry 79, no. 9 (2007): 3291-3297.

[23] F. Patosky, G. Zhang, C. M. Lieber, "Nanowire sensors for medicine and the life science." Nanomedicine 1, no 1 (2006): 51-65.

[24] L. Zeng, T. S. Zhao, L. An, “A high-performance supportless silver nanowire catalyst for anion exchange membrane fuel cells." Journal of Materials Chemistry A 3 (2015): 1410-1416.

[25] M. A. Kostowskyj, R.J. Gilliam, D.W. Kirk, S.J. Thorpe, "Silver nanowire catalysts for alkaline fuel cells.” International Journal of Hydrogen Energy 33, no 20 (2008): 5773-5778.

[26] I. Chang, T. Park, J. Lee, H. B. Lee, S. Ji, M. H. Lee, S. H. Ko, S. W. Cha. "Performance enhancement in bendable fuel cell using highly conductive Ag nanowires." International Journal of Hydrogen Energy 39, no. 14 (2014): 7422-7427.

[27] X. Cao, N. Wang, Y. Han, C. Gao, Y. Xu, M. Li, Y. Shao. "PtAg bimetallic nanowires: Facile synthesis and their use as excellent electrocatalysts toward low-cost fuel cells." Nano Energy 12 (2015): 105-114.

[28] Z. Xia, S. Wang, Y. Li, L. Jiang, H. Sun, S. Zhu, D. Su, G. Sun. "Vertically oriented polypyrrole nanowire arrays on Pd-plated Nafion ${ }^{\circledR}$ membrane and its application in direct methanol fuel cells.” Journal of Materials Chemistry A 1, no. 3 (2013): 491-494.

[29] E. Garnett, P. Yang. "Light trapping in silicon nanowire solar cells." Nano Letters 10, no. 3 (2010): 1082-1087.

[30] E. Garnett, M. L. Brongersma, Y. Cui, M. D. McGehee. "Nanowire solar cells." Annual Review of Materials Research 41 (2011): 269-295.

[31] Y. Cui, J. Wang, S. R. Plissard, A. Cavalli, T. TT. Vu, R. PJ van Veldhoven, L. Gao, "Efficiency enhancement of InP nanowire solar cells by surface cleaning." Nano Letters 13, no. 9 (2013): 4113-4117.

[32] X. Li, F. Gao, Z. Gu, "Nanowire Joining Methods." The Open Surface Science Journal 3 (2011): 91-104. 
[33] A. Vafaei, A. Hu, I. A. Goldthorpe, "Joining of individual silver nanowires via electrical current." Nano-Micro Letters 6, no. 4 (2014): 293-300.

[34] Q. Cui, F. Gao, S. Mukherjee, Z. Gu, "Joining and interconnect formation of nanowires and carbon nanotubes for nanoelectronics and nanosystems." Small 5, no. 11 (2009): 1246-1257.

[35] J. Lee, P.Lee, H. B. Lee, S. Hong, I. Lee, J. Yeo, S. S. Lee, T.Kim, D. Lee, S. H. Ko, "Silver Nanowires: Room-Temperature Nanosoldering of a Very Long Metal Nanowire Network by Conducting-Polymer-Assisted Joining for a Flexible Touch-Panel Application." Advanced Functional Materials 23, no. 34 (2013): 4165-4165.

[36] S. Ding, Y. Tian, Z. Jiang, C. Wang, "Joining of Silver Nanowires by Femtosecond Laser Irradiation Method." Materials Transactions 7 (2015): 981-983.

[37] P Peng, A Hu, H Huang A P. Gerlich, B. Zhao, Y. Norman Zhou, "Room-temperature pressureless bonding with silver nanowire paste: towards organic electronic and heat-sensitive functional devices packaging." Journal of Materials Chemistry 22, no. 26 (2012): 12997-13001.

[38] J. M. Patete, X. Peng, C. Koenigsmann, Y. Xu, B. Karnb, S. S. Wong, "Viable methodologies for the synthesis of high-quality nanostructures." Green Chemistry 13 (2011): 482-519.

[39] A. L. Tiano, C. Koenigsmann, A. C. Santullia, S. S. Wong, "Solution-based synthetic strategies for one-dimensional metal-containing nanostructures." Chemical Communications 46, no. 43 (2010): 8093-8130.

[40] S. Guo, S. Zhang, D. Su, S. Sun, "Seed-mediated synthesis of core/shell FePtM/FePt (M= $\mathrm{Pd}, \mathrm{Au})$ nanowires and their electrocatalysis for oxygen reduction reaction." Journal of the American Chemical Society 135, no. 37 (2013): 13879-13884.

[41] X. Zhou, Y. Zhou, J. C. Ku, C. Zhang, C. A. Mirkin. "Capillary force-driven, large-area alignment of multi-segmented nanowires." ACS Nano 8, no. 2 (2014): 1511-1516.

[42] X. Sun, F. Xu, Z. Li, W. Zhang. "Cyclic voltammetry for the fabrication of high dense silver nanowire arrays with the assistance of AAO template." Materials Chemistry and Physics 90, no. 1 (2005): 69-72.

[43] F. Gao, Fan, S. Mukherjee, Q. Cui, Z. Gu. "Synthesis, characterization, and thermal properties of nanoscale lead-free solders on multisegmented metal nanowires." The Journal of Physical Chemistry C 113, no. 22 (2009): 9546-9552. 
[44] C. Schönenberger, B. M. I. Van der Zande, L. G. J. Fokkink, M. Henny, C. Schmid, M. Krüger, A. Bachtold, R. Huber, H. Birk, and U. Staufer. "Template synthesis of nanowires in porous polycarbonate membranes: electrochemistry and morphology." The Journal of Physical Chemistry B 101, no. 28 (1997): 5497-5505.

[45] C.E.T. White, H, Okamoto, "Phase diagrams of indium alloys and their engineering applications”. Vol. 8. ASM Intl, 1992.

[46] Y. Zhu, X. Liu, H. Zhao, J. Wang. "Synthesis and electrochemical characterization of InSn4 and InSn4/C as new anode materials for lithium-ion batteries." Ionics 19, no. 5 (2013): 709-715. [47] Y. Shu, K. Rajathurai, F. Gao, Q. Cui, Z. Gu, "Synthesis and thermal properties of low melting temperature tin/indium ( $\mathrm{Sn} / \mathrm{In})$ lead-free nanosolders and their melting behavior in a vapor flux." Journal of Alloys and Compounds 626, (2015): 391-400.

[48] K. Soulantica, A. Maisonnat, F. Senocq, M. C. Fromen, M. J. Casanove, B. Chaudret, "Selective synthesis of novel in and $\mathrm{In}_{3} \mathrm{Sn}$ nanowires by an organometallic route at room temperature." Angewandte Chemie 113, no. 16(2001): 3071-3074.

[49] Y. Zhao, Z, Zhang, H. Dang, "Synthesis of In-Sn alloy nanoparticles by a solution dispersion method." Journal of Materials Chemistry 14, no.3 (2004): 299-302.

[50] F. Gao, K. Rajathurai, Q. Cui, G. Zhou, I. NkengforAcha, Z. Gu, "Effect of Surface Oxide on the Melting Behavior of Lead-free Solder Nanowires and Nanorods." Applied Surface Science 258 (2012): 7507-7514.

[51] Q. Y. Yin, F. Gao, Z. Gu, E. A. Stach, G. W. Zhou, "In-situ Visualization of Metallurgical Reactions in Nanoscale Cu/Sn Diffusion Couples.” Nanoscale 7 (2015): 4984-4994. 


\section{Graphical Abstract}

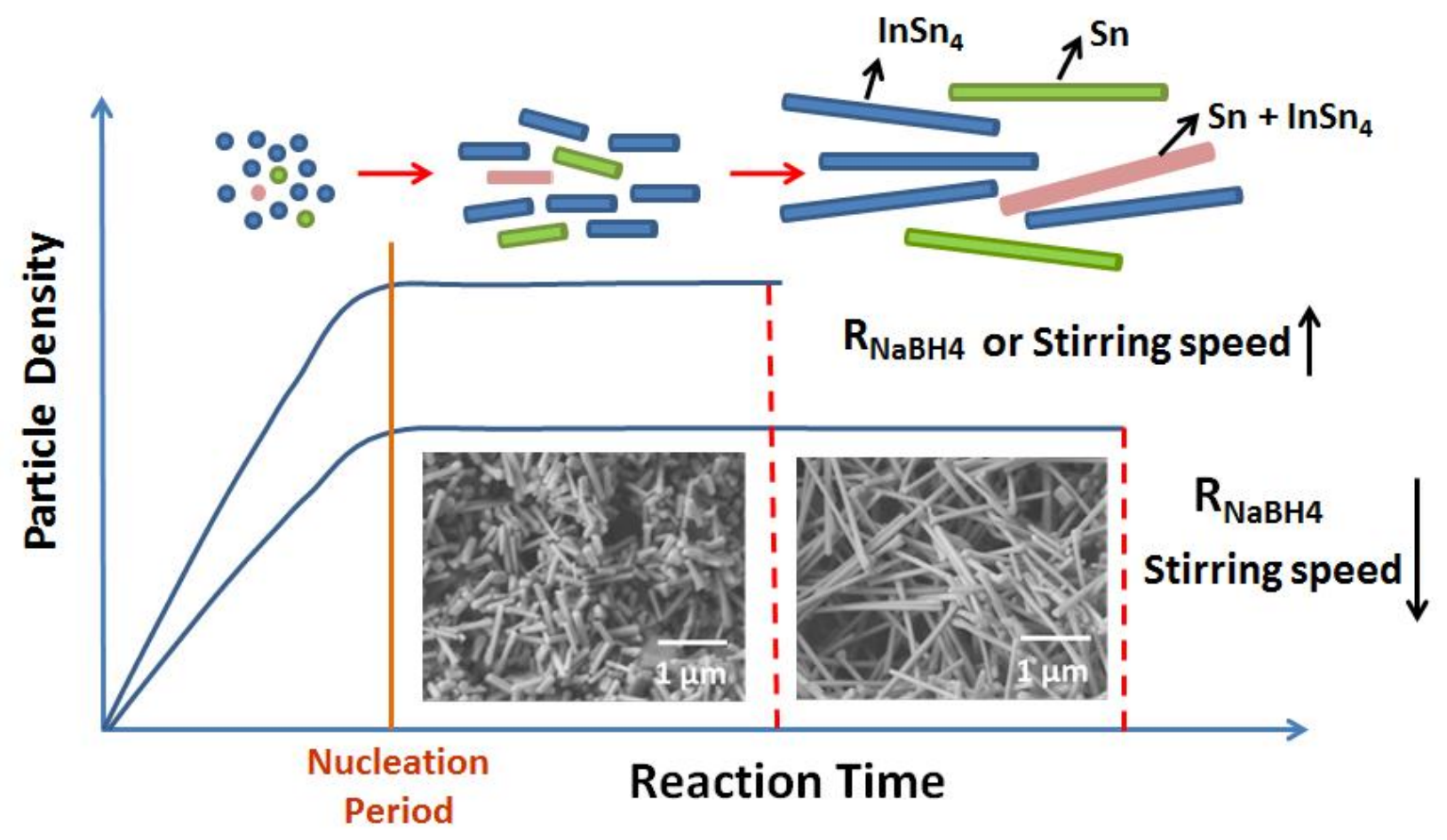

